\title{
Modification Mechanism of Asphalt Modified with Rock Asphalt and Styrene-Butadiene Rubber (SBR)
}

\author{
Xiangming Deng, ${ }^{1,2,3}$ Hui Huang $\mathbb{D}^{2,4}$ Bin Wang, ${ }^{2,4}$ and Jie Chen ${ }^{2,4}$ \\ ${ }^{1}$ Changsha University of Science and Technology, Changsha 410114, China \\ ${ }^{2}$ Guangxi Key Lab of Road Structure and Materials, Nanning 530007, China \\ ${ }^{3}$ Guangxi Communications Investment Group Corporation Ltd., Nanning 530022, China \\ ${ }^{4}$ Guangxi Transportation Science and Technology Group Co., Ltd., Nanning 530007, China \\ Correspondence should be addressed to Hui Huang; 88974719@qq.com
}

Received 4 February 2021; Revised 23 March 2021; Accepted 12 April 2021; Published 21 April 2021

Academic Editor: Jian Ji

Copyright (c) 2021 Xiangming Deng et al. This is an open access article distributed under the Creative Commons Attribution License, which permits unrestricted use, distribution, and reproduction in any medium, provided the original work is properly cited.

\begin{abstract}
High-performance asphalt binder plays an important role in the durable asphalt pavement. Asphalt modified by rock asphalt (RA) is one of the high-performance modified asphalt materials. It was used in road engineering as a relatively environmentally friendly material, because rock asphalt takes some advantages of large reserves, easy treatment, and efficient modification. Moreover, the main component of rock asphalt is bitumen, which enables it to substitute part of the binder used in asphalt mixtures. On the other hand, the negative low-temperature performance of RA modified asphalt impeded its application in cold regions. The object of this paper is to improve the low-temperature performance of RA modified asphalt by compound modified with styrene-butadiene rubber (SBR). The 70-penetration grade binder and the RA modified asphalt with 15\% RA by weight were applied as the base binder. Five types of RA-SBR modified asphalt were prepared, and the content of SBR was $2 \%, 4 \%, 5 \%, 6 \%$ and $8 \%$ by weight of BRA modified binder. The Fourier transform infrared spectroscopy (FTIR) tests were utilized to illustrate the reasons for the poor low-temperature performance of BRA modified asphalt and reveal the compound modification mechanism of BRA-SBR modified asphalt. The Brookfield viscosity test, dynamic shear rheometer test, and bending beam rheometer test were adopted to reveal the variation patterns of rheological behavior and low-temperature performance with mass contents of SBR. The test results indicated that the worse of low-temperature performance was caused by the increase of asphaltene content and the stress concentration due to ash in RA modified asphalt. And the compound modification is a physical process. The addition of SBR has improved the lowtemperature performance of RA modified asphalt dramatically. And based on the rheological behaviors and low-temperature performance of RA-SBR compound modified asphalt, the optimum content of SBR was determined, which is about $4 \% \sim 5 \%$.
\end{abstract}

\section{Introduction}

With the steadily growing axle loads and traffic volume, neat asphalt would fail to meet the requirements of durable pavement, unless it was well modified [1-3]. For example, SBS modified asphalt is the most popular modified asphalt, with both good performance of high- and low-temperature [4-7]. However, the production of most modifier and modified asphalt is complex and costly, resulting in an increase in fuel consumption and polluting gases [8-11]. Moreover, the dissolution of most modifiers with asphalt is not qualified enough, which disperses states of modifier in asphalt, segregation [12-15]. Therefore, most researchers have been committed to the development of economical and effective modifier.

Rock asphalt is a natural material, which is produced by impregnation of petroleum or oil into rocks such as limestone followed by the combined action of heat, pressure, oxidation, and bacteria over millions of years [16-18]. Obviously, the two predominant constituents of rock asphalt are asphaltene and mineral fillers, which are combined stably and guaranteed its good solubility in asphalt $[19,20]$. Rock asphalt has some advantages in terms of saving base asphalt, having lower cost, and being used easily during asphalt 
production without shearing, which reduced the resource consumption and polluting gases emission during pavements construction. One type of rock asphalt is Buton rock asphalt with a large number of reserves, which is widely used as a preferred modifier for asphalt in road engineering.

Buton rock asphalt is produced on the island of Buton, Indonesia, Southeast Asia. The asphaltene content of BRA is about $20 \%$, which could substitute part of asphalt binder used in asphalt mixture [21]. Previous research by other researchers has shown that Buton rock asphalt could act as a physical modifier to enhance honeycomb structure of the binder [22]. Multiple types of research and engineering also had proved that the addition of Buton rock asphalt could improve the performance of asphalt and asphalt mixtures, such as high-temperature performance, antiaging properties, antifatigue performance, and antisliding performance [23-25].

On the other hand, the low-temperature performances of BRA modified asphalt were unfavorable in comparison to the base binder [26]. So, some other additives were adopted by individuals as compound modifiers to modify the base binder accompanied by BRA to improve all kinds of performances. Two kinds of modifiers-styrene-butadiene rubber (SBR) and nano- $\mathrm{CaCO}_{3}$-were selected as the compound modifiers in Lv's research to improve the lowtemperature performances of BRA modified asphalt [27]. The results indicated that thermal crack resistance of BRA modified asphalt was improved dramatically with the addition of both SBR and nano- $\mathrm{CaCO}_{3}$, and the effects of SBR were better. Ren et al. investigated the effects of SBR on the properties of gilsonite modified asphalt and found that the compatibility and high- and low-temperature performance of gilsonite/SBR modified asphalt containing $30 \mathrm{wt} \%$ gilsonite realized the balance when the mixing content of SBR was about 7.5 wt\% [28]. Cai et al. used nanosilica, rock asphalt, and SBS to compose modified asphalt and found that nanosilica/rock asphalt/SBS modified asphalt mixture had higher temperature stability, low-temperature cracking resistance, moisture susceptibility, and durability than single modified asphalt [29]. In a word, the compound modification could keep the balance of high- and low-temperature performance of asphalt. SBR is supposed to be a preferable compound modifier of BRA modified asphalt, as it has advantages of lower cost and better cracking resistance. As mentioned above, there had been some researchers focusing on the mechanism for the better performance of BRA modified asphalt, but little existing research reveals the internal cause for the drop of low-temperature performance of BRA modified asphalt. Despite these significant research advancements in improving the low-temperature of BRA modified asphalt, rare research compares the changes of the components and microstructures of asphalt before and after modification.

In addition, the mechanisms of the variation of its performance could be revealed to verify the modification. Therefore, in this paper, SBR was employed to improve the low-temperature performance of BRA modified asphalt. The Fourier transform infrared spectroscopy (FTIR) tests were implemented to reveal the modification mechanism by determining the changes of the components of asphalt before and after modification. The Brookfield viscosity test, dynamic shear rheometer test, and bending beam rheometer were adopted to reveal the variation patterns of rheological behavior and low-temperature performance with mass contents of SBR, with which the optimum content of SBR could be obtained for the high-performance BRA-SBR modified asphalt.

\section{Objectives}

The main objectives of this research are as follows:

(1) To improve the low-temperature performance of BRA modified asphalt by compound modified with styrene-butadiene rubber (SBR).

(2) To reveal the modification mechanism of asphalt compound modified by BRA and SBR by changes of the components and functional groups of asphalt before and after modification.

(3) To analyze the effects of SBR on the road performances of BRA modified asphalt and determine the optimum content of SBR based on the variation patterns of mechanic parameters with the SBR content.

\section{Materials and Preparation}

3.1. Asphalt Binder. The asphalt binder of 70-penetration grade adopted in this research was produced in Wuhan province in China. Its specific technical properties were tested according to the Chinese Technical Specification for Construction of Highway Asphalt Pavements (JTG F40-2004), and the test results are in agreement with the requirement of standard specification and are presented in Table 1.

3.2. Buton Rock Asphalt. Buton rock asphalt used in this study was produced in Southeast Asia on the island of Buton, Indonesia. The asphaltene content of BRA is about $20 \%$, which could substitute part of the asphalt binder used in asphalt mixture. Moreover, Buton rock asphalt also takes advantage of compatibility with asphalt, improving the antiaging and durability of asphalt, and nonwax. The specific technical properties were tested according to the Chinese Standard Test Methods of Bituminous and Bituminous Mixtures for Highway Engineering (JTG E20-2011), and test results are presented in Table 2 . The test results showed that Buton rock asphalt meets all technical requirements in specifications.

3.3. Styrene-Butadiene Rubber. Styrene-butadiene rubber is a kind of synthetic rubber that has been proved to be an effective modifier for the low-temperature performance of asphalt. In this research, the SBR employed as a compound modifier was SBR 1502 rubber, which is specially produced for modifying asphalt by a company of Tianjin city in China. Its specific technical properties were tested according to the 
TABLE 1: Technical properties of asphalt binder of 70-penetration grade.

\begin{tabular}{|c|c|c|c|c|}
\hline Property & Units & Test results & Technical requirements & Specification \\
\hline Penetration $\left(25^{\circ} \mathrm{C}, 100\right.$ g. $\left.5 \mathrm{~s}\right)$ & $0.1 \mathrm{~mm}$ & 68.2 & $60-80$ & \multirow{2}{*}{ JTG E20 T0604 } \\
\hline Penetration index & / & -0.743 & $-1.5 \sim+1.0$ & \\
\hline Softening point $(\mathrm{R} \& \mathrm{~B})$ & ${ }^{\circ} \mathrm{C}$ & 49.1 & $\geq 46$ & JTG E20 T0606 \\
\hline Ductility at $15^{\circ} \mathrm{C}$ & $\mathrm{cm}$ & $>100$ & $>100$ & JTG E20 T0605 \\
\hline \multicolumn{5}{|c|}{ After TFOT $\left(163^{\circ} \mathrm{C}, 85 \mathrm{~min}\right)$} \\
\hline Mass loss & $\%$ & 0.15 & $\leq \pm 0.8$ & JTG E20 T0609 \\
\hline Residual penetration rate $\left(25^{\circ} \mathrm{C}\right)$ & $\%$ & 64 & $\geq 61$ & JTG E20 T0604 \\
\hline Residual ductility $\left(15^{\circ} \mathrm{C}\right)$ & $\mathrm{cm}$ & 8.1 & $\geq 6$ & JTG E20 T0605 \\
\hline
\end{tabular}

TABle 2: Technical properties of Buton rock asphalt.

\begin{tabular}{lccc}
\hline Property & Test result & Technical requirements & Specification \\
\hline Solubility in trichloroethylene (\%) & 25.8 & $>25$ & JTG E20 T0607 \\
Content of impurities such as soil (\%) & 0.8 & $<1$ & JTG E42 T0333 \\
Moisture content (\%) & 0.5 & 1 & JTG E42 T0332 \\
Ash content (\%) & 74.1 & $65-75$ & JTG E20 T0735 \\
Ash content difference in the same batch of samples (\%) & 0.4 & $\leq 1$ & JTG E20 T0735 \\
Ash content difference in the different batch of samples (\%) & 0.8 & $\leq 5$ & JTG E20 T0735 \\
Density $\left(\mathrm{g} / \mathrm{cm}^{3}\right)$ & 1.75 & $>1.6$ & JTG E42 T0328 \\
\hline
\end{tabular}

Chinese Standard of Rubber, styrene-butadiene-rubber (SBR) 1520 (GB12824), and the test results were presented in Table 3. Each indicator meets the Chinese specification.

3.4. Preparation of Modified Asphalt. Based on the previous research (reference), Buton rock asphalt could improve the high-temperature performance, durability, and moisture sensitivity of asphalt. The BRA modified asphalt would peak at the climax of comprehensive performance when the weight content of BRA was $15 \%$. Therefore, in this study, the content of the BRA was $15 \%$, and five different weight contents of SBR were $0 \%, 2 \%, 4 \%, 5 \%, 6 \%$, and $8 \%$. The asphalt binder of 70-penetration grade and BRA modified asphalt were applied as control samples.

The high-speed shear emulsifying machine was employed to mixing the base asphalt binder, BRA, and SBR to prepare BRA-SBR modified asphalt. The preparation procedure referred to Chinese Standard Test Methods of Bituminous and Bituminous Mixtures for Highway Engineering (JTG E20-2011), details presented in Figure 1.

(1) Heat the base binder stored in the metal cup by the oven to the temperature of $150^{\circ} \mathrm{C}$, and keep the temperature steady for an hour.

(2) Take out of the base binder from the oven, and put it on an electronic furnace to keep the temperature of the binder at a range of $160-170^{\circ} \mathrm{C}$, which is monitored by a thermometer inserted in the binder.

(3) Mix the base binder at the rotation rate of $1000 \mathrm{rpm}$, during which the weighted SBR was added into the base binder in several times. Then, the rotation speed is adjusted to $3000 \mathrm{rpm}$ after all SBR added into the binder, and keep mixing for $20 \mathrm{~min}$.

(4) Add the weighted BRA, and mix for half an hour.

\section{Experiment Plan}

4.1. Characteristic of Morphology and Microstructures. Fourier-transform infrared spectroscopy (FT/IR) can be applied to get the material structure and functional group of the solid, liquid, and gas according to its infrared absorbance spectrum [30]. In this study, the experimental equipment was BRUKER TENSOR II Fourier transform infrared spectrometer made by a German company. The scanning range recorded in this study was from $400 \mathrm{~cm}^{-1}$ to $4000 \mathrm{~cm}^{-1}$ wavenumber range with averaging 16 scans at a resolution of $4 \mathrm{~cm}^{-1}$. The scanning range was decided by the molecular structure of asphalt, shown in Table 4. The main wavenumber of the asphaltic material was presented in Table 4 .

During the FT/IR test, the equipment shines a beam containing the infrared frequency of light at once and measures how much of that beam is absorbed by the sample. This process is repeated many times. Afterwards, computer processing is required to turn the raw data (interferogram) into the desired result (light absorption for each wavenumber). By analyzing the absorbance of infrared in a certain region, the existence and intensity of specific functional groups can be identified. In this study, the BRUKER TENSOR II Fourier transform infrared spectrometer was adopted to assess the chemical changes of base binder treated with BRA, SBR, or BRA-SBR.

4.2. Characteristic of Rheological Performances at Different Temperatures. The rheological performance at different temperatures is usually thought to be a sensitive evaluation method to evaluate the temperature sensitivity and hightemperature performance. In this study, the Brookfield viscosity test and dynamic shear rheometer test were adopted to characterize the rheological performances of the asphalt at different temperatures. The Brookfield viscosity test was conducted under four experimental temperatures, 
TABLE 3: Technical properties of SBR 1502.

\begin{tabular}{lccc}
\hline Property & Test result & Technical requirement & Specification \\
\hline Content of butadiene (\%) & 70 & $68-71$ & GB12824-91 \\
Mooney viscosity & 52 & $50-53$ & GB12824-91 \\
Fineness with the mesh number of 10 (\%) & 100 & Mesh number of 10 or 20 & GB12824-91 \\
Styrene content (\%) & 23.5 & 23.5 & GB12824-91 \\
Volatilization (\%) & 0.2 & $\leq 0.8$ & GB12824-91 \\
Ash content (\%) & 7.5 & $\geq 26$ & GB12824-91 \\
Tensile strength & 26.5 & $\geq 500$ & GB-8655-88 \\
Elongation at break (\%) & 540 & $\leq 0.5$ & GB-8655-88 \\
Soap content (\%) & 0.15 & 6.3 & GB12824-91 \\
Content of organic acid (\%) & 6.3 & GB12824-91 \\
\hline
\end{tabular}

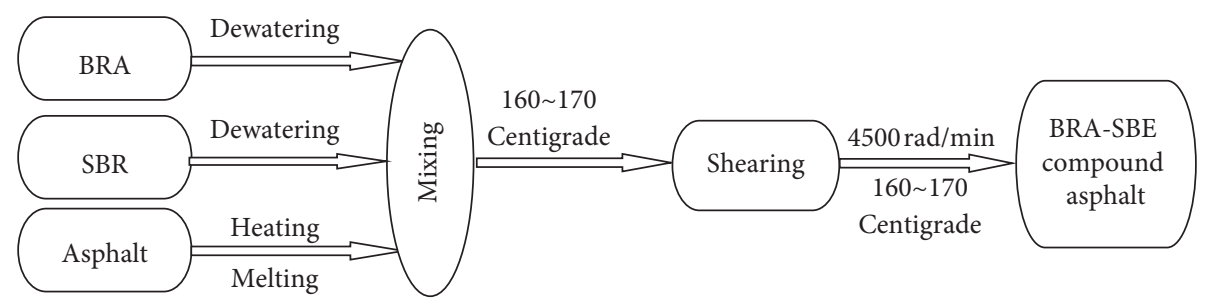

FIgURE 1: Production process of BRA-SBR compound modified asphalt.

TABLE 4: Assignations of the Main Bonds of FT/IR Spectra in the main compounds of asphalt.

\begin{tabular}{|c|c|c|}
\hline Peak items & Main wavenumber $\left(\mathrm{cm}^{-1}\right)$ & Vibrations \\
\hline Saturated hydrocarbon & $1475-700,1375-1380,1400,720$ & $\begin{array}{c}\mathrm{C}-\mathrm{H}, \mathrm{C}-\mathrm{C}, \mathrm{C}-\mathrm{CH} 3, \mathrm{H}-\mathrm{C}- \\
\mathrm{H},-\mathrm{CH} 2-\end{array}$ \\
\hline Aromatic hydrocarbon & $3030,1600-1500,1500-1480,1610-1500,1650-1600,1525-1450,2000-1670$ & $\mathrm{C}-\mathrm{H}, \mathrm{C}=\mathrm{C}$ \\
\hline Carboxyl compound & $\begin{array}{c}1725,1690,2820,2720,1700-1670,1690-1600,3550,3200-2500,1700-1680,920 \\
1860-1750,1740,1700,1300-1050,1210-1160\end{array}$ & $\mathrm{C}=\mathrm{O}, \mathrm{O}-\mathrm{H}, \mathrm{C}-\mathrm{O}-\mathrm{C}$ \\
\hline Hydroxy & $2700-2500$ & $-\mathrm{COOH}$ \\
\hline $\begin{array}{l}\text { Nitrogen-containing } \\
\text { compound }\end{array}$ & $3050,1690-1650,1640-1600,1400,1680-1655,1550-1530,1300,620$ & $\mathrm{C}-\mathrm{H}, \mathrm{C}-\mathrm{N}, \mathrm{O}=\mathrm{C}-\mathrm{N}$ \\
\hline $\begin{array}{l}\text { Sulfur-containing } \\
\text { compound }\end{array}$ & $2992-2955,2897-2869,1090,2590-2560,1065-1030,520-430$ & $\mathrm{~S}-\mathrm{C}, \mathrm{ArSH}, \mathrm{S}=\mathrm{O}, \mathrm{S}-\mathrm{S}$ \\
\hline
\end{tabular}

i.e., $135,145,165$, and $175^{\circ} \mathrm{C}$, with a rotation rate of $10 \mathrm{r} / \mathrm{min}$. The viscosity in different temperatures can be used to evaluate the temperature sensitivity and simulate the workability of the asphalt used in asphalt mixtures application for different seasons. Furthermore, the rheological behaviors of asphalt were evaluated by dynamic shear rheology (DSR) test. The Smart Pave Dynamic Shear Rheometer (DSR) was employed to investigate the performance of these three types of asphalt, e.g., rutting resistance. It is well known that rutting and stripping are the common distresses in asphalt pavements. The rutting indicator, $G * / \sin (\delta)$, of the asphalt was examined according to the Chinese Standard Test Methods of Bituminous and Bituminous Mixtures for Highway Engineering (JTG E20-2011). The initial test temperature was $40^{\circ} \mathrm{C}$, at which the complex shear moduli $G *$ and phase angle $\delta$ were measured. And then, the test temperature increased by $6^{\circ} \mathrm{C}$ each time, until the rutting indicator was less than $1 \mathrm{kPa}$.

4.3. Low-Temperature Performance Tests. The bending beam rheometer (BBR) creep test is usually thought to be the effective evaluation method to evaluate the low-temperature performance of asphalt according to the specification of Superpave. Therefore, BBR was employed to evaluate the lowtemperature performance of these three types of asphalt in this study. According to the Chinese Standard Test Methods of Bituminous and Bituminous Mixtures for Highway Engineering (JTG E20-2011), the stress-controlled procedure was conducted to obtain the creep stiffness $S(t)$ and parameter $m$ of the asphalt. The creep tests of the asphalt were carried out under different test temperatures, i.e., $-6^{\circ} \mathrm{C},-12^{\circ} \mathrm{C}$ and $-18^{\circ} \mathrm{C}$ by TE-BBR as shown in Figure 1. The size of the asphalt specimen test by TEBBR was $101.6 \mathrm{~mm} \times 12.7 \mathrm{~mm} \times 6.4 \mathrm{~mm}$, as Figure 2 showed. The loads and deformation in the testing process are automatically collected by the computer data acquisition system.

\section{Results and Discussions}

5.1. Fourier-Transform Infrared Spectroscopy Test. The base asphalt, BRA modified asphalt, and BRA-SBR compound modified asphalt were analyzed through the FTIR test. The infrared spectra of these three types of asphalt are shown in Figure 3. 


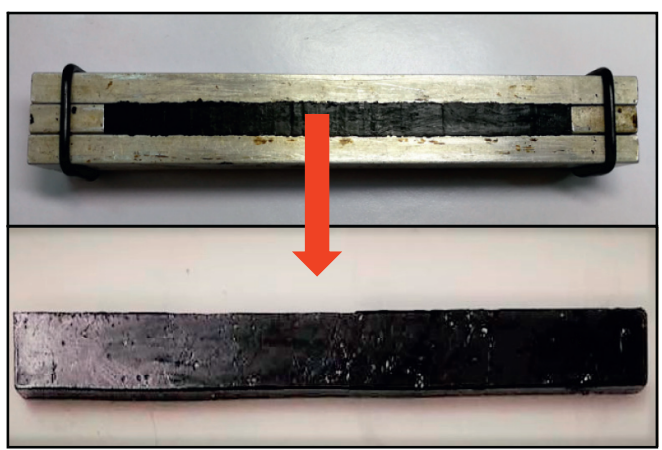

(a)

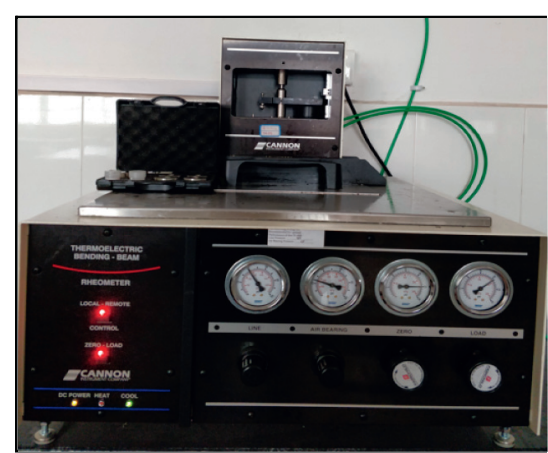

(b)

FIGURE 2: Thermoelectric bending beam rheometer and specimen.

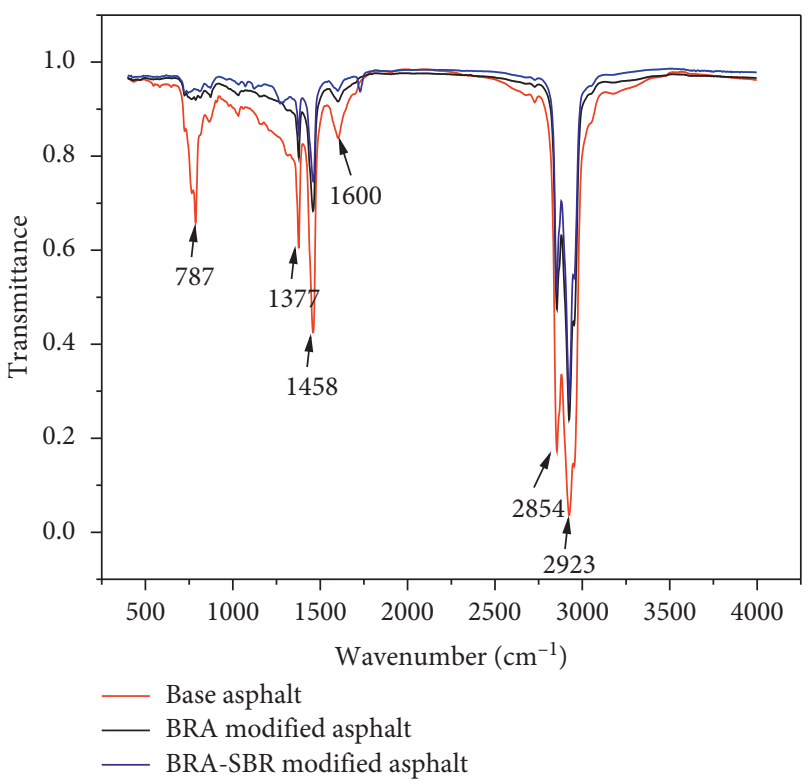

FIgURE 3: Infrared spectra of three types of asphalt.

FTIR methodology can detect molecular vibrations. From the infrared spectra, the material information on chemical bonding and material structure can be obtained. As can be seen from Figure 3, it is obvious that the infrared spectra of base asphalt differed from the BRA modified asphalt and BRA-SBR compound modified asphalt. Many peaks were smaller after modification, and no new peaks were generated. This denoted that the content of some compounds was decreased, and the modification was a physical reaction. The peak at $787 \mathrm{~cm}^{-1}$ decreased dramatically, and this peak was the extrinsic bending vibrations of $\mathrm{C}-\mathrm{H}$ in Alkene. The peak at $1377 \mathrm{~cm}^{-1}$, the peak at $1458 \mathrm{~cm}^{-1}$ 1 , and the peak at $1600 \mathrm{~cm}^{-1}$ were the $\mathrm{C}=\mathrm{C}$ ring stretch from aromatic compounds.

5.2. Brookfield Viscosity Test. Usually, the series of viscosity tests are designed to determine the mixing and compaction temperature for asphalt mixtures. On the other hand, the various properties of viscosity with temperature have thought to be an effective method to evaluate the temperature sensitivity of asphalt. The Brookfield viscosity of BRA-SBR modified asphalt with different contents of SBR was measured under four selected test temperatures in this study. The test results are presented in Figure 4.

As can be seen in Figure 3, the addition of SBR had an obvious effect on the viscosity of BRA-SBR modified asphalt. In a certain threshold of SBR content and the selected test temperatures, the viscosity varied with the content of SBR in three stages. First, the viscosity declined slightly but obviously, when the BSR content increased from $0 \%$ to $4 \%$. Then, the decreasing rate increased when the BSR content increased from $4 \%$ to $6 \%$, and the valley values occurred when the SBR content was $6 \%$. After the content of SBR exceeded $6 \%$, the changing trend of viscosity altered and increased with the increase of SBR content. When the content of SBR exceeded 6\%, it was becoming difficult for SBR to diffuse in asphalt uniformly, which contributes to the increase of the viscosity of BRA-SBR modified asphalt.

Meanwhile, it was also observed that when the test temperature became higher, the rate in which viscosity decreased with SBR content was visibly smaller. The viscosity of BRA-SBR modified asphalt with $6 \%$ SBR, where the viscosity was at the valley value and was about $0.077 \mathrm{~Pa} \cdot \mathrm{s}$ smaller than that of asphalt with $2 \%$ SBR at the test temperature of $135^{\circ} \mathrm{C}$, while at the temperature of $175^{\circ} \mathrm{C}$, it was $0.027 \mathrm{~Pa} \cdot \mathrm{s}$.

The viscosity-temperature index (VTS) was adopted to evaluate the temperature sensitivity of asphalt, and the greater the VTS, the worse the temperature sensitivity. Viscosity-temperature curve and index were obtained by regression and fitting, which guarantee the precision of VTS while comparing with other methods. The Brookfield viscosity test results were fitted with test temperature by equation (1), and the fitting results could be found in Figure 5 and Table 5.

It is observed from Table 5 that the VTS of BRA-SBR modified asphalt changed with the addition of SBR. The VTS increased with the increase of SBR contents before the SBR content exceeded 6\%, after which the VTS decreased but still larger than that of BRA modified asphalt. It indicated that the addition of SBR aggravated the temperature sensitivity and the high-temperature stability of BRA modified asphalt. But the temperature sensitivity and the high-temperature 


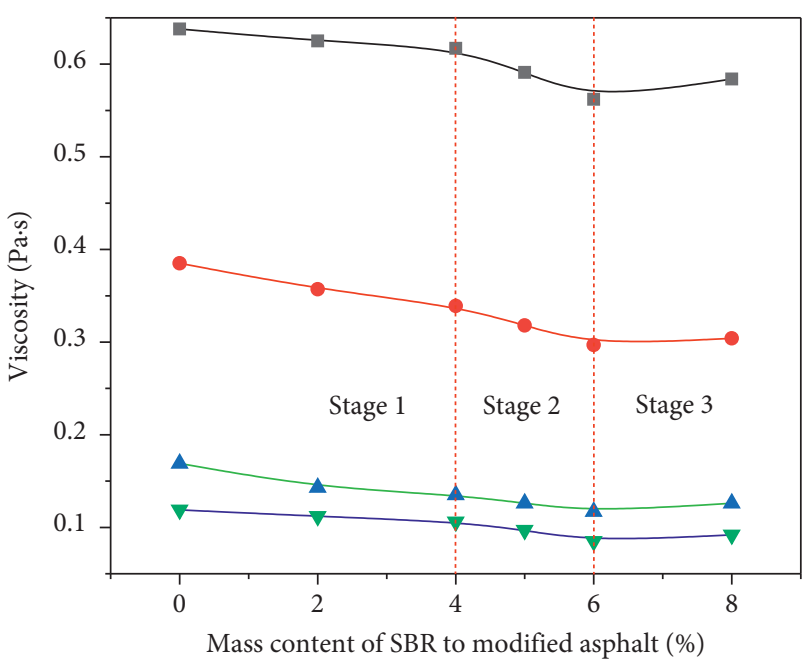

Test temperature

$$
\begin{array}{ll}
-\square-135^{\circ} \mathrm{C} & -\boldsymbol{-}-165^{\circ} \mathrm{C} \\
-\bullet-145^{\circ} \mathrm{C} & -\nabla-175^{\circ} \mathrm{C}
\end{array}
$$

FIGURE 4: Variation patterns of brookfield viscosity with SBR contents.

stability of BRA-SBR modified asphalt were still better than those of base asphalt and even than SBS modified asphalt according to previous researches.

5.3. Dynamic Shear Rheology Test. As shown in the Brookfield viscosity test results, the addition of SBR has a significant influence on the temperature stability of BRA modified asphalt. In order to reveal the effects of SBR on the viscoelastic properties and the antirutting performance, the dynamic shear rheology (DSR) test was conducted for the BRA-SBR modified asphalt with different SBR contents. The test results were presented in Figure 6 and Figure 7.

As can be seen in Figure 6, the phase angle of all the asphalt increased with the increase of test temperatures. The phase angle has usually been thought as an indicator to reflect the viscoelastic properties, and the greater phase angle means greater viscous portion. Under the same test temperature, the phase angle increased with the content of SBR, which implied that the addition of SBR improved the elasticity properties of asphalt.

On the other hand, the rutting indicators were calculated to reveal the influences of SBR on the BRA modified asphalt. The higher value of rutting indicators indicates a better hightemperature performance. Figure 6 displayed the $G * / \sin (\delta)$ of BRA-SBR modified asphalt with different contents of SBR. It could be observed that the $G * / \sin (\delta)$ of all the asphalt declined with the increase of test temperatures and decreased slowly after $64^{\circ} \mathrm{C}$. Meanwhile, at the same test temperature, the $G * / \sin (\delta)$ increased with the increase of the SBR content. It suggested that the resistance to rutting was reduced with the rise of temperature but improved with the addition of SBR.

The distress of asphalt pavement like rutting usually occurred in summer when the temperature of pavement was about $60^{\circ} \mathrm{C}$. The test temperatures of DSR were

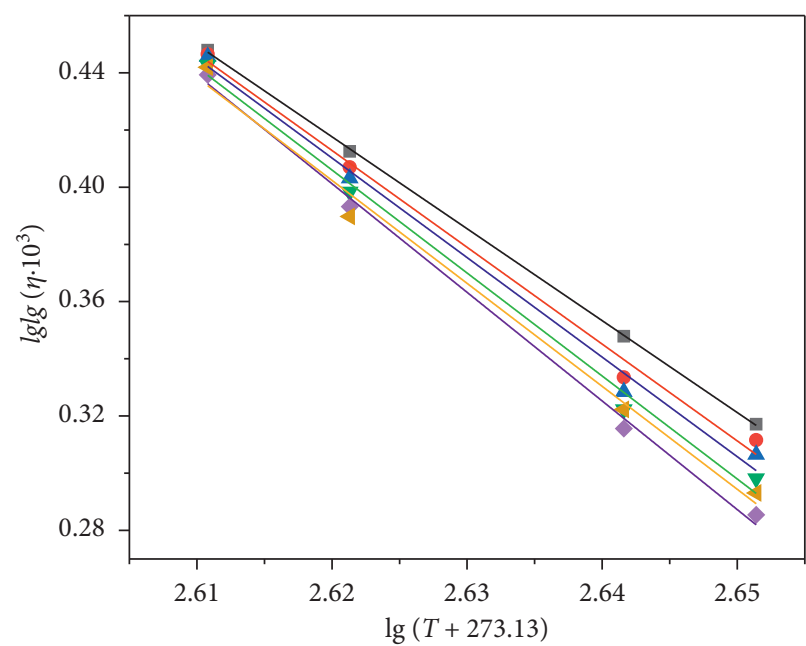

SBR contents

$\begin{array}{lr}-0 \% & \nabla 5 \% \\ -2 \% & >6 \% \\ -4 \% & <8 \%\end{array}$

FIGURE 5: Viscosity-temperature curves of BRA-SBR modified asphalt with different SBR contents.

TABLE 5: The fitting results of the viscosity-temperature curve for BRA-SBR modified asphalt.

\begin{tabular}{lcccccc}
\hline \multirow{2}{*}{ Parameters } & \multicolumn{5}{c}{ SBR content (\%) } \\
& 0 & 2 & 4 & 5 & 6 & 8 \\
\hline$M$ & 3.21 & 3.39 & 3.48 & 3.60 & 3.80 & 3.61 \\
$N$ & 8.84 & 9.28 & 9.53 & 9.84 & 10.35 & 10.25 \\
$R^{2}$ & 0.97 & 0.94 & 0.96 & 0.92 & 0.95 & 0.94 \\
\hline
\end{tabular}

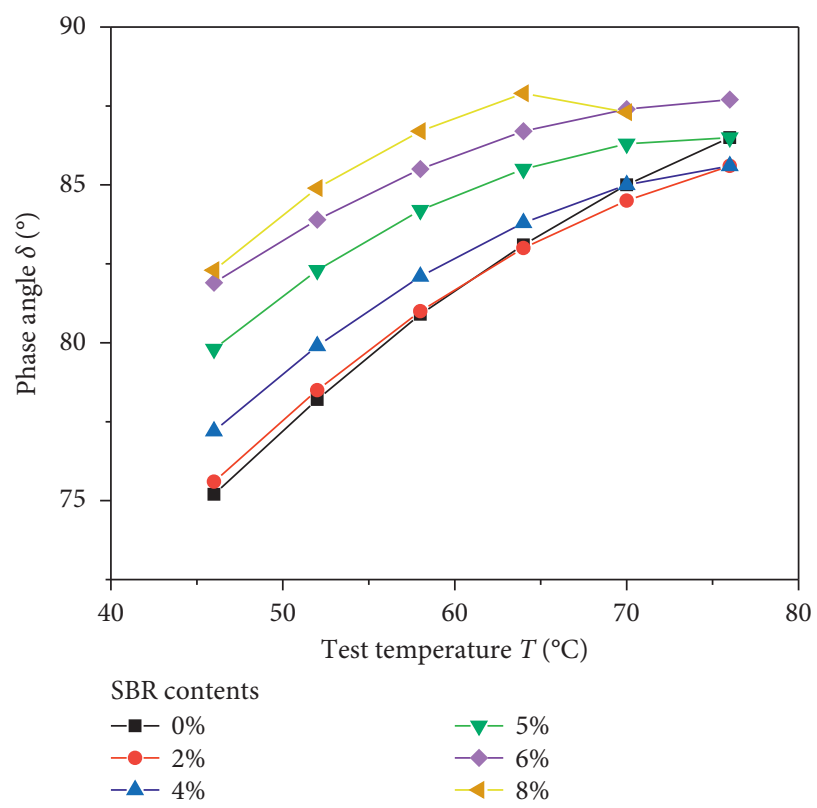

FIgURE 6: The variation patterns of phase angle and test temperatures. 


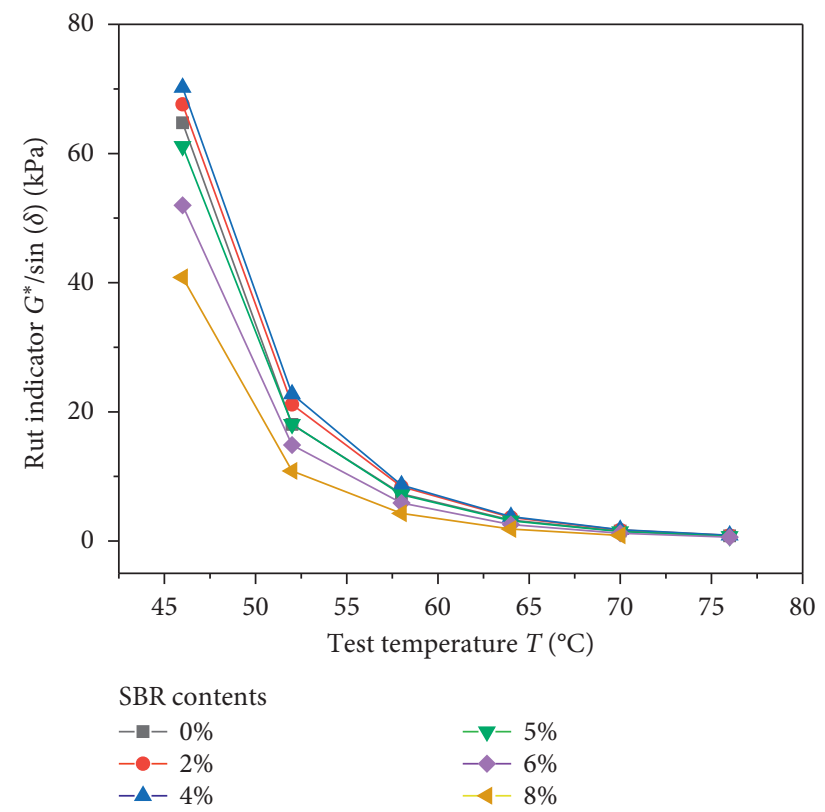

Figure 7: The variation patterns of rutting indicators and test temperatures.

approximately similar to the temperature of the pavement in summer. So, it has been thought that the variation pattern of $G^{*} / \sin \delta$ during this range of temperature was more suitable to evaluate the temperature stability of asphalt used in road engineering than penetration or Brookfield viscosity. According to reference [30], the $\mathrm{G}^{*} / \sin \delta$ was fitted by equation (1) in double natural logarithmic coordinates, and the fitting results were presented in Figure 8 and Table 6.

$$
\lg \lg \left(\eta \times 10^{3}\right)=n-m \lg (T+273.13) .
$$

As can be seen in Figure 8, the slope of the curve quantified by the parameter $a$ in equation (1) could reflect the change rate of $G^{*} / \sin \delta$ with test temperature. So, the parameter could be adopted as an index to evaluate the temperature sensitivity of asphalt. It is obviously observed from Table 6 that the change rate became down with the increase of SBR content, which meant that the temperature stability of BRA-SBR modified asphalt improved with the content of SBR.

5.4. Bending Beam Rheometer (BBR) Creep Test. According to the specification of Superpave, the low-temperature performance of asphalt binder is qualified when its creep stiffness is less than $300 \mathrm{MPa}$, and the $m$-value is larger than 0.3 . The bending beam rheometer creep test results of BRA modified asphalt modified with different content of SBR were presented in Table 7.

Based on the results, it could be found that the addition of SBR has a significant influence on the low-temperature performance of BRA modified asphalt. The creep stiffness $S_{t}$ decreased with the content of SBR dramatically. Under the SBR content of $2 \%, 4 \%, 5 \%, 6 \%$, and $8 \%$, the creep stiffness of BRA modified asphalt decreased about 14.5\%, 27.7\%, 43.0\%, $48.6 \%$, and $53.4 \%$, respectively. As to the creep rate, the $m$ value increased with the content of SBR obviously. Under the

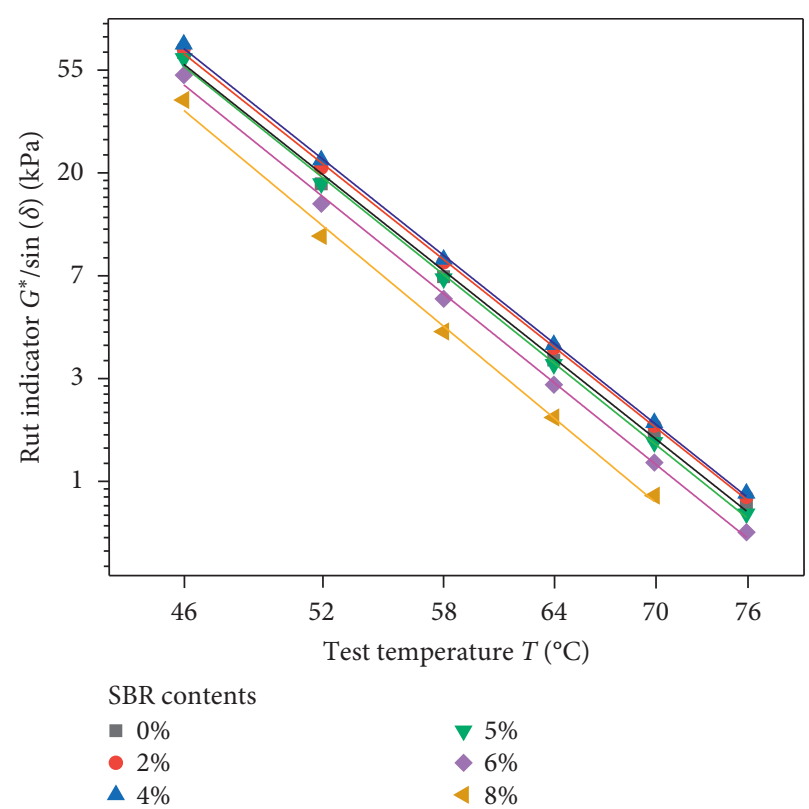

FIgURE 8: The variation patterns of rutting indicators and test temperatures.

TABle 6: Fitting results of $G * / \sin (\delta)$ with test temperature.

\begin{tabular}{lcccccc}
\hline \multirow{2}{*}{ Parameters } & 0 & 2 & 4 & 5 & 6 & 8 \\
\hline$a$ & -8.65 & -8.63 & -8.68 & -8.74 & -8.77 & -9.06 \\
$b$ & 37.19 & 37.21 & 37.42 & 37.48 & 37.42 & 38.30 \\
$R^{2}$ & 0.98 & 0.97 & 0.99 & 0.99 & 0.98 & 0.96 \\
\hline
\end{tabular}

SBR content of $2 \%, 4 \%, 5 \%, 6 \%$, and $8 \%$, and the $m$-value of BRA modified asphalt increased about $8.6 \%, 14.3 \%, 21.9 \%$, $28.9 \%$, and $35.9 \%$, respectively. 
TABLE 7: BBR test results of BRA-SBR compound modified asphalt.

\begin{tabular}{|c|c|c|c|c|c|c|c|}
\hline \multicolumn{2}{|c|}{ Content of SBR (\%) } & 0 & 2 & 4 & 5 & 6 & 8 \\
\hline \multirow{3}{*}{$\mathrm{S}(\mathrm{MPa})$} & $-6^{\circ} \mathrm{C}$ & 248 & 214 & 181 & 143 & 129 & 117 \\
\hline & $-12^{\circ} \mathrm{C}$ & 523 & 437 & 377 & 298 & 266 & 248 \\
\hline & $-18^{\circ} \mathrm{C}$ & - & - & - & 631 & 582 & 524 \\
\hline \multirow{3}{*}{ M } & $-6^{\circ} \mathrm{C}$ & 0.301 & 0.327 & 0.344 & & 0.388 & 0.409 \\
\hline & $-12^{\circ} \mathrm{C}$ & 0.253 & 0.265 & 0.290 & 0.327 & 0.333 & 0.346 \\
\hline & $-18^{\circ} \mathrm{C}$ & - & - & - & 0.263 & 0.271 & 0.289 \\
\hline \multirow{3}{*}{ S/M (MP-1) } & $-6^{\circ} \mathrm{C}$ & 0.001209 & 0.001535 & 0.001911 & 0.002585 & 0.003031 & 0.003526 \\
\hline & $-12^{\circ} \mathrm{C}$ & 0.000485 & 0.000608 & 0.000771 & 0.001101 & 0.001257 & 0.001401 \\
\hline & $-18^{\circ} \mathrm{C}$ & - & - & - & 0.000417 & 0.000466 & 0.000552 \\
\hline
\end{tabular}

\section{Conclusions}

Waste rubber caused many environment problems nowadays, and waste rubber is mainly generated from waste tires and rubber track in the athletic field. In this paper, styrenebutadiene rubber (SBR), the main component of rubber, is introduced as a modifier to improve the low-temperature performance of BRA modified asphalt. Five types of BRASBR modified asphalt were prepared, and the content of SBR was $2 \%, 4 \%, 5 \%, 6 \%$, and $8 \%$ by weight of BRA modified binder. The modification mechanism was revealed by Fourier transform infrared spectroscopy (FTIR) tests. And the road performance, including high and low-temperature performance, was evaluated by Brookfield viscosity test, dynamic shear rheometer test, and bending beam rheometer test. Some conclusions could be drawn from this study as follows.

(1) According to the results of FTIR test, there was no new functional group generated, only reduction of some functional group, which meant that the modification of BRA and SBR to asphalt is a physic modification.

(2) The change rate of $G * / \sin \delta$ with test temperature could be adopted as an index to evaluate the temperature sensitivity of asphalt, and the temperature stability of BRA-SBR modified asphalt improved with the content of SBR.

(3) SBR has an apparent influence on the low-temperature performance of BRA modified asphalt when the content was within a certain range. Based on the high- and low-temperature performance, the content of SBR was recommended to be about $4 \%-5 \%$.

\section{Data Availability}

All data generated or analyzed during this study are included in this published article.

\section{Conflicts of Interest}

The authors declare no conflicts of interest.

\section{Authors' Contributions}

Conceptualization was done by Xiangming Deng and Hui Huang. Experiment was done by Hui Huang, Bin Wuang, and Jie Chen. Data curation was performed by Xiangming Deng, Hui Huang, and Jie Chen. Formal analysis was performed by Xiangming Deng, Hui Huang, and Jie Chen. Funding acquisition was done by Hui Huang. Methodology was done by Xiangming Deng and Hui Huang. Project administration was performed by Xiangming Deng and Hui Huang. Resources were provided by Xiangming Deng and Hui Huang. Validation was done by Hui Huang. The original draft was written by Xiangming Deng and Hui Huang.Reviewing and editing were performed by Xiangming Deng, Hui Huang, Bin Wuang, and Jie Chen.

\section{Acknowledgments}

This study was supported by Guangxi Key Science and Technology Project (Nos. AA18242032, AB20297030, and AB19245019) and Science and Technology Project of Guangxi Housing and Urban Construction Department (2018-2-2).

\section{References}

[1] S. Lv, C. Liu, D. Chen, J. Zheng, Z. You, and L. You, "Normalization of fatigue characteristics for asphalt mixtures under different stress states," Construction and Building Materials, vol. 177, pp. 33-42, 2018.

[2] E. Cicek, "The effects of different types of fibres and geotextiles for pavement design," Road Materials and Pavement Design, vol. 20, no. 4, pp. 793-814, 2019.

[3] C. C. Liu, S. T. Lv, X. H. Peng, J. L. Zheng, and M. Yu, "Analysis and comparison of different impacts of aging and loading frequency on fatigue characterization of asphalt concrete," Journal of Materials in Civil Engineering, vol. 32, no. 9, Article ID 04020240, 2020.

[4] D. Zhang, Z. Chen, H. Zhang, and C. Wei, "Rheological and anti-aging performance of SBS modified asphalt binders with different multi-dimensional nanomaterials," Construction and Building Materials, vol. 188, pp. 409-416, 2018.

[5] R. He, S. H. Wu, X. F. Wang, Z. J. Wang, and H. X. Chen, "Temperature sensitivity characteristics of SBS/CRP-Modified bitumen after different aging processes," Materials, vol. 11, no. 11, p. 2136.

[6] T. Nian, P. Li, X. Wei, P. Wang, H. Li, and R. Guo, "The effect of freeze-thaw cycles on durability properties of SBS-modified bitumen," Construction and Building Materials, vol. 187, pp. 77-88, 2018.

[7] Z. L. Li, X. Xu, J. Y. Yu, and S. P. Wu, “Assessment on physical and rheological properties of aged SBS modified bitumen 
containing rejuvenating systems of isocyanate and Epoxy substances," Materials, vol. 12, no. 4, p. 618.

[8] B. Li, Y. J. Cui, X. Liu, H. L. Li, and X. M. Li, "Effect of material composition on nano-adhesive characteristics of styrenebutadiene-styrene copolymer-modified bitumen using atomic force microscope technology," International Journal of Adhesion and Adhesives, vol. 89, pp. 168-173, 2019.

[9] M. Saltan, S. Terzi, and S. Karahancer, "Mechanical behavior of bitumen and hot-mix asphalt modified with zinc oxide nanoparticle," Journal of Materials in Civil Engineering, vol. 31, no. 3, Article ID 04018399, 2019.

[10] D. Zheng, Z.-D. Qian, P. Li, and L.-B. Wang, "Performance evaluation of high-elasticity asphalt mixture containing inorganic nano-titanium dioxide for applications in high altitude regions," Construction and Building Materials, vol. 199, pp. 594-600, 2019.

[11] Y. Gong, H. Bi, Z. Tian, and G. Tan, "Pavement performance investigation of nano- $\mathrm{TiO} 2 / \mathrm{CaCO} 3$ and basalt fiber composite modified asphalt mixture under freeze-thaw cycles," Applied Sciences, vol. 8, no. 12, p. 2581, 2018.

[12] S. Eskandarsefat, G. Dondi, and C. Sangiorgi, "Recycled and rubberized SMA modified mixtures: a comparison between polymer modified bitumen and modified fibres," Construction and Building Materials, vol. 202, pp. 681-691, 2019.

[13] A. Behnood and M. Modiri Gharehveran, "Morphology, rheology, and physical properties of polymer-modified asphalt binders," European Polymer Journal, vol. 112, pp. 766-791, 2019.

[14] A. Diab, M. Enieb, and D. Singh, "Influence of aging on properties of polymer-modified asphalt," Construction and Building Materials, vol. 196, pp. 54-65, 2019.

[15] G. Cuciniello, P. Leandri, S. Filippi, D. Lo Presti, M. Losa, and G. Airey, "Effect of ageing on the morphology and creep and recovery of polymer-modified bitumens," Materials and Structures, vol. 51, no. 5, p. 136, 2018.

[16] I. Widyatmoko and R. Elliott, "Characteristics of elastomeric and plastomeric binders in contact with natural asphalts," Constrution and Building Material, vol. 22, no. 3, pp. 239-249, 2005.

[17] M. Yilmaz and M. E. Çeloğlu, "Effects of SBS and different natural asphalts on the properties of bituminous binders and mixtures," Construction and Building Materials, vol. 44, pp. 533-540, 2013.

[18] Z. F. Lu, Z. Y. He, Q. Yu, and G. Huang, "Influence of rock asphalt modified bitumen on asphalt rheological property," Journal of ChongQingJiaoTong University (Natural Science), vol. 28, pp. 543-547, 2009.

[19] A. Sassan and T. Nader, "Proposals for modification of Iranian bitumen to meet the climatic requirements of Iran," Constrution and Building Material, vol. 23, no. 6, pp. 21412150, 2009.

[20] M. Ameri, A. Mansourian, S. S. Ashani, and G. Yadollahi, "Technical study on the Iranian gilsonite as an additive for modification of asphalt binders used in pavement construction," Construction and Building Materials, vol. 25, no. 3, pp. 1379-1387, 2011.

[21] J. Jin, Y. Gao, Y. Wu et al., "Rheological and adhesion properties of nano-organic palygorskite and linear SBS on the composite modified asphalt," Powder Technology, vol. 377, pp. 212-221, 2021.

[22] Y. F. Li, J. Chen, J. Yan, and M. Guo, "Influence of buton rock asphalt on the physical and mechanical properties of asphalt binder and asphalt mixture," Advances in Materials Science and Engineering, vol. 2018, Article ID 2107512, 7 pages, 2018.
[23] S. Liu, W. Cao, X. Li, Z. Li, and C. Sun, "Principle analysis of mix design and performance evaluation on Superpave mixture modified with Buton rock asphalt," Construction and Building Materials, vol. 176, pp. 549-555, 2018.

[24] S. P. Hadiwardoyo, E. S. Sinaga, and H. Fikri, "The influence of Buton asphalt additive on skid resistance based on penetration index and temperature," Construction and Building Materials, vol. 42, pp. 5-10, 2013.

[25] G. L. Zou and C. Wu, "Evaluation of rheological properties and field applications of Buton rock asphalt," Journal of Testing and Evaluation, vol. 43, no. 5, Article ID 20130205, 2015.

[26] R. Li, P. Karki, P. Hao, and A. Bhasin, "Rheological and low temperature properties of asphalt composites containing rock asphalts," Construction and Building Materials, vol. 96, pp. 47-54, 2015.

[27] C. C. Liu, S. T. Lv, D. Z. Jin, and F. T. Qu, "Laboratory investigation for the road performance of asphalt mixtures modified by rock asphalt/styrene butadiene rubber," Journal of Materials in Civil Engineering, vol. 33, no. 3, Article ID 04020504, 2021.

[28] S. Ren, M. Liang, W. Fan et al., "Investigating the effects of SBR on the properties of gilsonite modified asphalt," Construction and Building Materials, vol. 190, pp. 1103-1116, 2018.

[29] L. Cai, X. Shi, and J. Xue, "Laboratory evaluation of composed modified asphalt binder and mixture containing nano-silica/ rock asphalt/SBS," Construction and Building Materials, vol. 172, pp. 204-211, 2018.

[30] H. Wei, J. Li, F. Wang, J. Zheng, Y. Tao, and Y. Zhang, "Numerical investigation on fracture Evolution of asphalt mixture compared with acoustic emission," International Journal of Pavement Engineering, pp. 1-11, 2021. 